\title{
O TEMPO DE RESIDÊNCIA E DE CONTACTO COM A CRIANÇA APÓS DIVÓRCIO OU SEPARAÇÃO Experiências de mães e de pais
}

\author{
Sofia Marinho \\ ICS-UL, Lisboa, Portugal
}

Resumo O artigo examina as práticas e os significados subjetivos que dividem o tempo parental e como estes moldam papéis parentais, identidades e a relação com a criança quer nas experiências de mães e pais separados, quer na aplicação da Lei do Divórcio N. 61/2008. Com base num inquérito online, revela-se que a lei é resistida e manteve o uso do género para alocar tempo parental no regime de residência e contacto. Neste, as mães residentes vivem a relação entre a gratificação afetiva e identitária e a sobrecarga parental. Ao invés, os pais não residentes lidam com a privação parental e a submissão à paternidade tradicional. No regime de residência alternada abraça-se a partilha parental e os desafios da concertação educativa, nem sempre aceites na aplicação da Lei.

Palavras-chave: regime de residência e contacto, regime de residência alternada, responsabilidades parentais, tempo parental.

\begin{abstract}
The article explores the practices and subjective meanings that allocate parenting time and its influence in shaping parental roles, identity and the relationship with the child both among separated mothers and fathers, and in divorce law. Drawing on an online survey, results reveal that the law preserves the use of gender to allocate parental time in the regime of residence and contact. In this regime, resident mothers experience the interplay between affective and identity gratification, and parental overload. Instead, nonresident fathers cope with parental deprivation and submission to traditional fathering. In the regime of shared residence, parents are engaged both in equal parenting and in the challenges of adjusting different parenting styles, which are not always accepted by the law.
\end{abstract}

Keywords: residence and contact, shared residence, parental responsibility, parenting time.

Résumé L'article analyse les pratiques et les significations qui divisent le temps parental et comment ils configurent les rôles parentaux, les identités et la relation avec l'enfant, dans les expériences des mères et des pères, ainsi que dans l'application de la Loi du divorce 61/2008. Une enquête réalisée en ligne révèle une résistance de la loi en maintenant le critère de genre pour attribuer le temps parental dans le régime de résidence et de contact. Les mères qui ont la garde des enfants vivent la relation entre gratification affective et identitaire et surcharge. Les pères non-résidents vivent la privationparentale et la soumission à la paternité traditionnelle. Quant à la résidence alternée, elle implique le partage parental et soulève les défis de la concertation éducative, pas toujours acceptés par la loi.

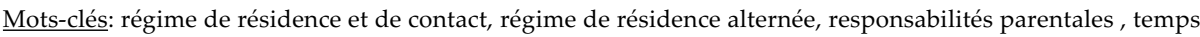
parental.

Resumen El artículo examina las prácticas y los significados subjetivos que dividen el tiempo parental y cómo éstos modelan papeles parentales, identidades y la relación con el niño sea entre madres y padres, sea en la aplicación de la Ley del Divorcio N. 61/2008. Sobre la base de una encuesta en línea, se desprende que la ley es resistida y ha mantenido el uso del género para asignar tiempo parental en el régimen de custodia exclusiva. En este, las madres residentes viven la relación entre la gratificación afectiva e identitaria y la sobrecarga parental. En cambio, los padres no residentes se ocupan de la privación parental y la sumisión a la paternidad tradicional. En el régimen de residencia alternada se aboga por el reparto parental y los desafíos de la concertación educativa, no siempre aceptados en la aplicación de la Ley.

Palabras-clave: custodia exclusiva, custodia compartida, responsabilidades parentales, tiempo parental. 


\section{Introdução}

A experiência do divórcio ou da separação conjugal acarreta a redefinição das práticas de divisão do tempo parental entre progenitores e dos significados que mães e pais atribuem ao tempo que estão envolvidos com as crianças. Principalmente porque a alocação do tempo parental após rutura conjugal, ou seja, o tempo do envolvimento com as crianças, é institucionalmente orientada pela distinção entre residência com a criança e regime de visitas da criança, configurando este o tempo de contacto com o progenitor não residente.

No estudo da parentalidade após divórcio, deu-se grande atenção à análise da frequência do envolvimento do pai no tempo de contacto, encontrando-se uma correlação entre o afastamento do pai, o regime de contacto quinzenal de pequena duração e o tipo de guarda legal. Neste contexto analítico, ganharam relevância duas visões do tempo de contacto. Uma destaca a importância da duração e calendarização deste tempo, salientando que as dormidas da criança facultam variedade e continuidade às interações do quotidiano (deitar, levantar, cuidar, refeições, levar e ir buscar à escola, estudar, lazeres, etc.), sendo deste modo essenciais para a construção de uma relação envolvida e próxima entre a criança e os dois progenitores (Kruk, 2015; Smyth, 2004; Nielsen, 2011). Outra evidencia as barreiras colocadas pela curta duração do tempo de contacto ao envolvimento pleno de progenitores não residentes na educação da criança e nas responsabilidades parentais (Hallman, Dienhart e Beaton, 2007; Kruk, 2015; Neyrand, 2009).

Ambas são sustentadas por investigação que realça quer os custos materiais, sociais e emocionais do afastamento paterno e da curta duração do tempo de contacto, tanto para crianças, como para mães e pais (Arendell, 1995; Kruk, 2015), quer a importância do tempo de envolvimento paterno para o bem-estar das crianças (Lamb, 2010; Nielsen, 2014; O’Brien, 2004).

Investigação recente identifica alterações em curso na divisão da alocação do tempo parental entre progenitores, que se fazem sentir quer na conjugalidade (Rodrigues, Cunha e Wall, 2015) quer após divórcio ou separação (Nielsen, 2014). Realça que estas traduzem lógicas decorrentes tanto do duplo emprego no casal, como de novos modelos culturais de relações entre a maternidade, a paternidade e o tempo dedicado à criança, fomentadoras de novas expectativas sobre o papel do pai e da mãe nos afetos, nos cuidados e na educação de filhas e filhos (Marinho, 2011; Neyrand, 2009).

No plano institucional, atendeu-se à manutenção do envolvimento dos dois progenitores nas responsabilidades e no tempo parental, considerando-se o seu papel central no bem-estar infanto-juvenil após divórcio. A construção social deste novo "interesse" da criança deu lugar a uma reforma legislativa que, ao introduzir princípios de partilha parental na legislação de vários países ocidentais, materializou, com ritmos e particularidades variadas, duas novas modalidades de guarda das crianças: a guarda legal partilhada, referente à partilha de responsabilidades parentais no quadro da residência com um progenitor e regime de visitas ao outro, e a guarda legal partilhada com residência alternada, em que a criança reside entre $33 \%$ a $50 \%$ do tempo com um progenitor e o restante tempo com o outro, no quadro da partilha de responsabilidades parentais. 
A influência destas novas modalidades de guarda na intensidade do envolvimento paterno e na cooperação e no conflito parental tem sido largamente estudada. Porém, deu-se pouca atenção ao impacto da aplicação de princípios legais de partilha parental no tempo efetivo de residência e de contacto da criança com os progenitores. Defende-se, neste texto, que falta perceber algumas questões: se as crianças passaram a beneficiar de uma maior partilha do tempo parental; em que medida esta partilha lhes faculta a diversidade de contextos de interação com os dois progenitores necessária ao seu bem-estar (Kruk, 2010; Nielsen, 2014); e se as mães e os pais estão a referenciar as suas experiências do tempo com os/as filhos/as à relação entre partilha parental e bem-estar da criança proposta na reforma legal.

Este artigo investiga estes processos sociais, tendo como base empírica um inquérito online respondido por 114 mães e pais portugueses, divorciados/separados. Debruça-se sobre as práticas e os significados associados por mães e por pais à divisão do tempo parental e sobre o papel das suas experiências do tempo com os/as filhos/as na forma como encaram os papéis paterno e materno e o relacionamento de cada progenitor com a criança.

Recorre a abordagens teóricas do lugar do tempo na organização e na experiência familiar (Daly, 1996) e da relação entre o tempo e as lógicas de construção e desconstrução do género na família (Deutsch, 2007; Morgan, 2011). Desta forma, coloca no centro da análise os significados subjetivos, os valores e as normas sociais imbuídos nas práticas e experiências do tempo parental de homens e mulheres e, ao mesmo tempo, os quadros simbólicos e as estruturas sociais em que se inserem (Daly, 1996; Hallman, Dienhart e Beaton, 2007; Hodgson, Dienhart e Daly, 2001).

O próximo ponto debruça-se sobre o modo como a sociedade portuguesa abraçou princípios legais de partilha parental e sobre o estudo das experiências da divisão do tempo parental no divórcio/separação. Após uma secção que descreve a metodologia e a amostra do estudo, o artigo averigua as práticas, os significados e as experiências do tempo parental de mães e de pais portugueses.

\section{Enquadramento legal, processos sociais e estudos do tempo parental}

A introdução de normas de partilha parental na legislação portuguesa inicia-se em 1995, dando-se aos progenitores a opção de exercerem o poder paternal conjunto, no quadro do regime-regra de poder paternal único, geralmente materno, ao qual estava associada a residência com a criança (Lei N.. 84/95, de 31 agosto). Culmina na Lei N. ${ }^{\circ} 61 / 2008$, de 31 outubro, que substitui o conceito legal de poder paternal pelo de responsabilidades parentais, separando o exercício destas da residência com a criança. A lei estabelece como regime-regra o exercício conjunto das responsabilidades parentais quanto às questões de maior importância para o interesse da criança, combinando-o com o exercício exclusivo quanto aos atos da vida corrente pelo progenitor com quem esta reside. Protege a manutenção do contacto da criança com os dois progenitores, ao limitar a aplicação do exercício exclusivo de todas as responsabilidades parentais às situações de abuso, violência ou negligência parental (Oliveira, 
2017). Institui, assim, um regime-regra de partilha das responsabilidades parentais legais com residência com um progenitor e visitas ao outro, em tudo semelhante ao denominado, em outros países, de guarda legal partilhada (Nielsen, 2011). A possibilidade de a criança residir alternadamente com os dois progenitores não é introduzida na lei por esta reforma.

Os Censos 2011 mostram lógicas de continuidade na residência das crianças com a mãe após rutura conjugal. Com efeito, os núcleos familiares de mãe só, resultantes do divórcio ou da separação, registaram até um pequeno aumento: de $88,5 \%$, em 2001, para 89,2\%, em 2011 (Marinho, 2014). E nos núcleos familiares recompostos os filhos e as filhas não comuns ao casal residem sobretudo com a mãe (Atalaia, 2014).

O estudo de Pedroso, Casaleiro e Branco (2014: 92 e 95), sobre os Tribunais de Família e Menores de Braga e Lisboa, indica que tais lógicas de continuidade estão associadas a práticas judiciais. Nestes tribunais, em 2010, a guarda era atribuída sobretudo à mãe. Em Lisboa, prevalecia a atribuição de responsabilidades parentais partilhadas $(60 \%)$, mas a de responsabilidades exclusivas da mãe representava $29 \%$ dos acordos. Já em Braga, a atribuição de responsabilidades exclusivas à mãe era predominante.

Face a estes dados, parece ser indubitável que a residência materna e o contacto paterno permanecem como regime padrão nas representações e práticas de casais e de atores judiciais. Porém, paralelamente, desde 1995, vários são os juízes e magistrados que têm atribuído ou homologado residências alternadas no âmbito da atribuição de responsabilidades parentais partilhadas (Marinho, 2011, 2017), e estas estão a ganhar terreno nas escolhas dos casais, o que é colocado pelos resultados apresentados neste artigo. Assim, também existem evidências de que algo está a mudar na divisão do tempo parental, sem substituir práticas e representações sociais antigas, é certo, mas relativizando as certezas que as moldavam e criando diversidade.

Para compreender estes processos importa olhá-los à luz da construção sócio-histórica do modelo de divisão social do trabalho do homem ganha-pão e da mulher cuidadora e doméstica. Mas também das tensões sociais emergentes do seu declínio, por via da emergência de modelos de duplo emprego e duplo cuidar, quer no plano institucional quer no das práticas e da identidade parental de mães e de pais (Escobedo, Flaquer e Navarro-Varas, 2012; Neyrand, 2009). No plano da identidade parental, o que está em causa são processos subjetivos de identificação e de distanciamento a diferentes formas de ser mãe e de ser pai, bem como a relação destes com a diversificação da ordem de significações que define a maternidade e a paternidade e os papéis sociais que as desenham (Marinho, 2011; Kaufmann, 1994). Com efeito, o regime de residência materna e visitas paternas transpõe para o pós-divórcio a naturalização da referenciação dos papéis sociais e da identidade de cada sexo a funções diferenciadas segundo estereótipos de género, na reprodução, na vida familiar, no mercado de trabalho e na vida pública em geral (Neyrand, 2009; Smyth, 2004). Como explica Daly (1996), este processo está entrelaçado com a construção social de significados para a relação entre o género e as dimensões temporais da separação entre a vida privada e pública e, nesta medida, das 
manifestações desta relação nos valores e nas normas sociais relativas ao tempo das mulheres e dos homens com as suas crianças. Destas, decorre a transposição para o pós-divórcio do entendimento do tempo familiar materno como o tempo do dia a dia das tarefas de cuidar, educar e conciliar família, trabalho e escola das crianças durante a semana, e do tempo familiar paterno como o tempo das atividades lúdicas e dos lazeres ao fim de semana, de contacto com o pai provedor e companheiro de brincadeiras, como afirma Singly (2000).

Contudo, tal entendimento mostra-se cada vez mais desajustado, seja face ao duplo emprego no casal, seja perante modelos culturais orientadores de maternidades igualitárias e de paternidades relacionais e envolvidas, ou seja, da maior proximidade e investimento quotidiano do pai na criança (Escobedo, Flaquer e Navarro-Varas, 2012; Neyrand 2009), seja, ainda, face à atribuição de elementos afetivos, relacionais e identitários ao tempo das atividades domésticas quotidianas passado com filhos e filhas (Marinho, 2011).

A influência da relação entre tempo quantificável e tempo social nas experiências de envolvimento de pais não residentes foi investigada por Hallman, Dienhart e Beaton (2007). O estudo revela o desfasamento entre o desejo de tempo do dia a dia com a criança e a realidade do tempo concentrado ao fim de semana vivido pelos pais. As experiências do tempo parental estão ancoradas em sentimentos de perda de acesso à criança, bem como na impossibilidade de acompanhar de perto o desenvolvimento desta e de influenciar a sua educação. Mas também na perceção do tempo enquanto direito a um bem emocional e identitário valioso, para o pai e a criança, que precisa de ser adquirido através da pensão de alimentos e defendido de visões deficitárias do papel paterno. Os autores concluem que a quantidade do tempo parental influencia a capacidade de o homem desempenhar um papel parental e a sua identidade como pai, o que, por sua vez, molda as experiências do tempo com a criança.

Kruk (2015) revela que as mães não residentes também se sentem desprovidas do acesso à criança, da manutenção de laços significativos e do seu papel e identidade parental, indicando que a quantidade de tempo de contacto é vivida do mesmo modo por homens e mulheres, sendo, portanto, desadequada para ambose para as crianças. Assinala, ainda, que o papel de mãe não residente é alvo do estigma da "má mãe", enquanto o do pai não residente é socialmente aceite, desde que este não aspire a mais tempo parental.

Pelo seu lado, as experiências do tempo parental de mães residentes tendem a ser desenhadas pelos "tempos de plantão parental" e pelos "tempos libertos de crianças" (Hodgson, Dienhart e Daly, 2001). Segundo as autoras, os primeiros são pautados quer pela prioridade dada à parentalidade e aos momentos de qualidade com as crianças, quer pela sobrecarga inerente à articulação de múltiplas tarefas e responsabilidades na vida familiar com o trabalho - também documentada por Cardoso (2014) no caso português. Os segundos, reportam-se aos fins de semana paternos, em que o tempo dos ritmos domésticos é mais flexível e convidativo ao lazer.

Na residência alternada, as experiências de mães e de pais são também pautadas pelos ritmos do tempo com e sem crianças, mas, na medida em que nela existe 
uma maior partilha do tempo parental entre progenitores, são menos habitadas por tais sentimentos de sobrecarga ou de dificuldade na articulação do tempo para as crianças, para si e para o trabalho (Neyrand, 2009).

Smyth (2004) é dos poucos autores que se debruça sobre os efeitos dos princípios legais de partilha parental na alteração dos tempos efetivos de residência e de contacto da criança com cada progenitor. Olhando para o caso australiano, verifica que os tempos curtos de contacto tendem a permanecer, quer por hábito quer por razões práticas, mantendo uma estrutura de impedimento da manutenção de laços próximos entre a criança e o progenitor não residente. Contudo, mães e pais estão também a aumentar períodos de contacto com dormidas e a partilhar cuidados por via da alternância de residência.

\section{Metodologia}

Este artigo baseia-se num inquérito online, aplicado em 2014-2015, sobre as perceções, práticas e atitudes de pais e de mães divorciados ou separados, por um lado, e sobre as suas características familiares, demográficas e socioeconómicas, por outro.

Os participantes foram recrutados pelo método de "bola de neve" e pela divulgação do inquérito em redes sociais, empresas, escolas e associações. O preenchimento estava limitado a três condições: (1) estar divorciado/separado há mais de um ano; (2) ter pelo menos um/a filho/a menor de 16 anos de uma relação terminada; e (3) que o/a filho/a tivesse contacto com os dois progenitores. Pediu-se aos participantes que tivessem em conta apenas a criança mais nova nas suas respostas.

A análise centrou-se nos seguintes eixos de observação: (1) tempo passado pela criança com cada progenitor e formas de calendarização do tempo parental; (2) avaliação das mães e dos pais das suas vivências da divisão do tempo parental; (3) regime legal de responsabilidades parentais; e (4) características sociodemográficas e da vida familiar dos/as respondentes.

No primeiro eixo, a variável tempo de residência e de contacto contabiliza o número de noites (0-30) que a criança dorme na casa da mãe e do pai, durante a semana e o fim de semana, num mês típico do período letivo (2014-2015). A partir deste procedimento, e tendo em conta a classificação de formas de residência e de contacto apresentadas na literatura (por exemplo: Bastaits, Ponnet e Mortelmans, 2012; Nielsen, 2011), foram identificadas três modalidades de residência e uma de contacto, com a seguinte distribuição: $17 \%$, residência única com contacto sem dormidas ( $100 \%$ das dormidas com um progenitor); $30 \%$, residência padrão (73-93\% das dormidas com um progenitor); $37 \%$, residência alternada (33-50\% das dormidas com um progenitor); e, 16\%, não residência com contacto padrão (6-26\% das dormidas com um progenitor). Assim, as situações de residência com a criança são definidas como aquelas em que esta dorme, no mínimo, dez noites em cada mês na casa do progenitor. O estudo não inclui não residentes com contacto sem dormidas ou sem contacto com o/a filho/a durante o período letivo. 
De forma a identificar os contextos temporais de interação da criança com os progenitores, observou-se a calendarização do tempo parental nas respostas à seguinte questão aberta: "Explique a forma de organização da rotação dos períodos em que o seu/sua filho/a dorme na sua casa e na casa do pai/da mãe e os motivos da organização escolhida." Observou-se ainda a divisão do tempo parental nas férias de verão (dividido, só com um progenitor).

O segundo eixo captou as experiências do tempo parental através da seguinte questão aberta: "Fazendo um balanço, aponte e explique quais os aspetos negativos e positivos do modo de guarda do seu filho ou filha." Aqui, a amostra ficou reduzida a 80 casos, dadas as não respostas e seis respostas que, por serem parcas em palavras (p. ex.: "cansativo"), foram excluídas da análise temática qualitativa.

O terceiro eixo olhou para as responsabilidades parentais negociadas no momento da separação. Esta variável inclui acordos parentais regulados no tribunal (45\%), homologados em conservatórias do Registo Civil (31\%) e informais (24\%). A maioria dos acordos, $80 \%$, foi negociada no quadro da Lei N. ${ }^{6}$ 61/2008. As responsabilidades parentais legais também informam sobre a residência e o contacto com a criança, porém não permitem medir o tempo que esta passa realmente com cada progenitor. Assim, esta variável foi utilizada para aferir a relação entre tipos legais de responsabilidade parental (partilhada ou exclusiva) e de residência (residência e não residência, ou residência alternada).

Por fim, o quarto eixo mobiliza variáveis da vida familiar e sociodemográficas, analisando variáveis associadas às modalidades de residência e de contacto encontradas: o grupo etário da criança $(p<0,05)$; o sexo $(p<0,001)$; e a escolaridade dos/as participantes ("até ao 12. ${ }^{\circ}$ ano" e "licenciatura ou mais") ${ }^{1},(\mathrm{p}<0,01)$. Assim, as mães e os pais separados com escolaridades baixas não estão incluídos neste estudo. Isto deve-se, eventualmente, quer à divulgação do inquérito por via de mailing lists, que dificulta o controlo da escolaridade dos respondentes por parte da investigadora, quer ao requisito de os respondentes possuírem equipamentos e conhecimentos informáticos para preencherem um inquérito online.

Os procedimentos analíticos foram pautados pela combinação da análise estatística descritiva e inferencial de variáveis categoriais, com a análise temática qualitativa do conteúdo de respostas a questões abertas.

\section{Amostra}

A amostra é não probabilística e não representativa da população de mães e de pais separados/divorciados. É constituída por 114 progenitores, dos quais $73 \%$ são mulheres e $27 \%$ são homens, separados/as ( $41 \%$ ) ou divorciados/as $(59 \%)$, a maioria (80\%) depois da Lei N. ${ }^{6} 61 / 2008$. Apenas $21 \%$ das mães possuem escolaridades até ao

1 A primeira categoria inclui o $11 .^{\circ}$ e o $12 . .^{\circ}$ anos e a segunda inclui licenciaturas, mestrados, pós-graduações e doutoramentos. 
12.. ano, face a $45 \%$ dos pais. As mães com escolaridades ao nível de "licenciatura ou mais" representam $79 \%$ da amostra e os pais $55 \%$.

A idade da criança mais nova distribui-se pelos seguintes grupos etários: $32 \%$ até 6 anos; $48 \%$ com 7-11 anos; e 20\% com 12-16 anos. A idade média dos participantes é 39 anos e a do outro progenitor é 40 anos. A maioria das parcerias parentais (75\%) residia na área metropolitana de Lisboa, distribuindo-se as restantes pela zona Norte (9\%), Centro (6\%) e Sul (8\%) do país.

\section{A residência e o contacto da criança com os progenitores}

O número de dormidas da criança em casa de cada progenitor, durante a semana e o fim de semana, num mês típico do período letivo, configura, nesta amostra, três modalidades de residência e uma de não residência com contacto padrão, ou seja, de contacto com dormidas da criança na casa do progenitor não residente (figura 1). Estas representam dois regimes distintos de divisão do tempo das crianças com cada progenitor, que coexistem na sociedade portuguesa: o de residência e não residência com contacto com a criança, que apelidei regime standard, seguindo a classificação de standard package avançada por Smyth (2004); e o de a residência alternada.

Como indica a figura 1, vivem crianças de todas as idades nos dois regimes, mas as crianças no grupo etário dos 7-11 anos tendem a estar mais representadas na residência alternada $(\mathrm{p}<0,05)$. No regime standard, as crianças residem sobretudo com as mães, quer em residência padrão quer em residência única, repetindo-se nesta amostra as tendências reveladas pelos Censos 2011 (Marinho, 2014). No regime de residência alternada, as crianças residem com os dois progenitores. Vejamos então quais são as principais características de cada regime.

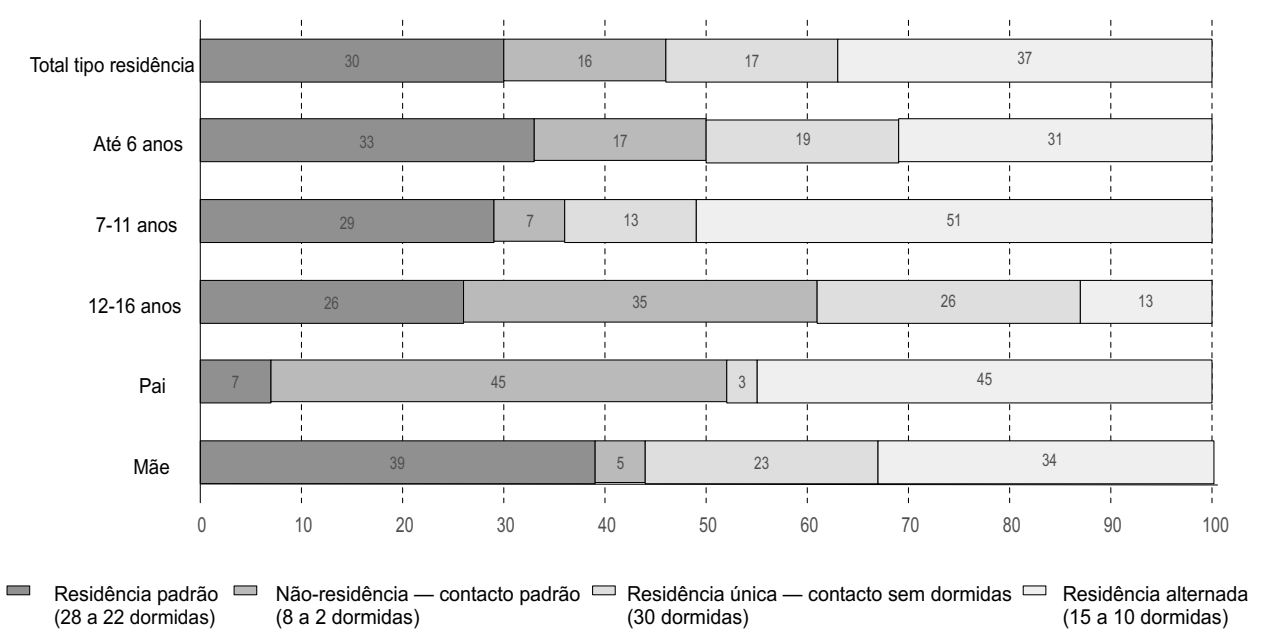

Figura 1 Formas de residência e de contacto, segundo o número de dormidas, o grupo etário da criança e o sexo do/a respondente (\%) 


\section{O regime standard: residência e não residência com contacto}

A conjugação entre residência e não residência materializa o regime jurídico de $r e-$ sidência e visitas. Este diferencia o envolvimento de cada progenitor nos cuidados e na educação da criança através da alocação de tempo parental: o tempo de residência e o de contacto. O contacto pode estabelecer-se através de dormidas na casa do progenitor não residente, situação que apelidei não residência com contacto padrão. Mas também pode não incluir dormidas, estabelecendo-se só durante o dia, quer de forma regular em fins de semana quinzenais, quer de forma irregular e esporádica, configurando a residência única com contacto sem dormidas, que abordarei mais à frente.

A residência e contacto padrão é configurada por quatro modalidades de divisão do tempo da criança com cada progenitor: 28-2; 26-4; 24-6; e 22-8 (figura 2). Nestas, só $42 \%$ das crianças tendem a passar férias de verão com os dois progenitores $(\mathrm{p}<0,001)$. Vejamos exemplos de como são organizadas.

Na modalidade 28-2, o contacto com o pai ocorre em uma dormida quinzenal. Este vai buscar a criança a casa da mãe ao sábado, a seguir ao almoço, e leva-a de volta no domingo, após o lanche. Noutros casos, vai buscá-la à escola à sexta-feira e leva-a a casa da mãe no sábado à tarde. Na modalidade 26-4, a mais representada na amostra (18\%), o contacto ocorre em duas dormidas quinzenais. O pai vai buscar a criança à escola à sexta-feira e leva-a a casa da mãe no domingo à tarde. Nalguns casos, a meio da semana seguinte jantam juntos. Na modalidade 24-6, a criança dorme seis noites por mês na casa do pai. À sexta-feira este vai buscá-la à escola, e no domingo à tarde leva-a a casa da mãe. Na quarta-feira seguinte, esta volta a dormir em casa do pai. Finalmente, a modalidade 22-8 inclui oito dormidas na casa do pai. Quinzenalmente, à sexta-feira, o pai vai buscar a criança à escola e na segunda-feira volta a deixá-la na escola. Na quarta-feira seguinte, esta dorme em casa do pai.

Os períodos de contacto com o pai são, assim, muito curtos, concentram-se ao fim de semana e implicam separações longas, principalmente nas duas primeiras modalidades. As modalidades 24-6 e 22-8 revelam a introdução de uma dormida a meio da semana no tempo de contacto, o que diminui o tempo de ausência e permite ao pai conhecer melhor a criança, através da participação no acompanhamento escolar e nos cuidados no final do dia de escola. Porém, como assinala Kruk (2015), trata-se de uma participação de curta duração e descontinuada no tempo, insuficiente para a responsabilização parental do progenitor não residente. Ao aumentar também as dormidas ao fim de semana, a modalidade 22-8 configura uma prática emergente no quadro da aplicação da nova lei.

A curta duração do tempo parental alocado à paternidade não residente e a concentração deste no fim de semana evidencia que, neste regime, o envolvimento parental paterno é circunscrito a alguns domínios de responsabilidade parental e de interação com a criança, mesmo quando inclui uma dormida quinzenal a meio da semana. É justamente do que falam os homens quando avaliam as suas experiências do contacto. Com efeito, só apresentam aspetos negativos, partilhando entre si a insatisfação com a duração do tempo que lhes é permitido estar com as 


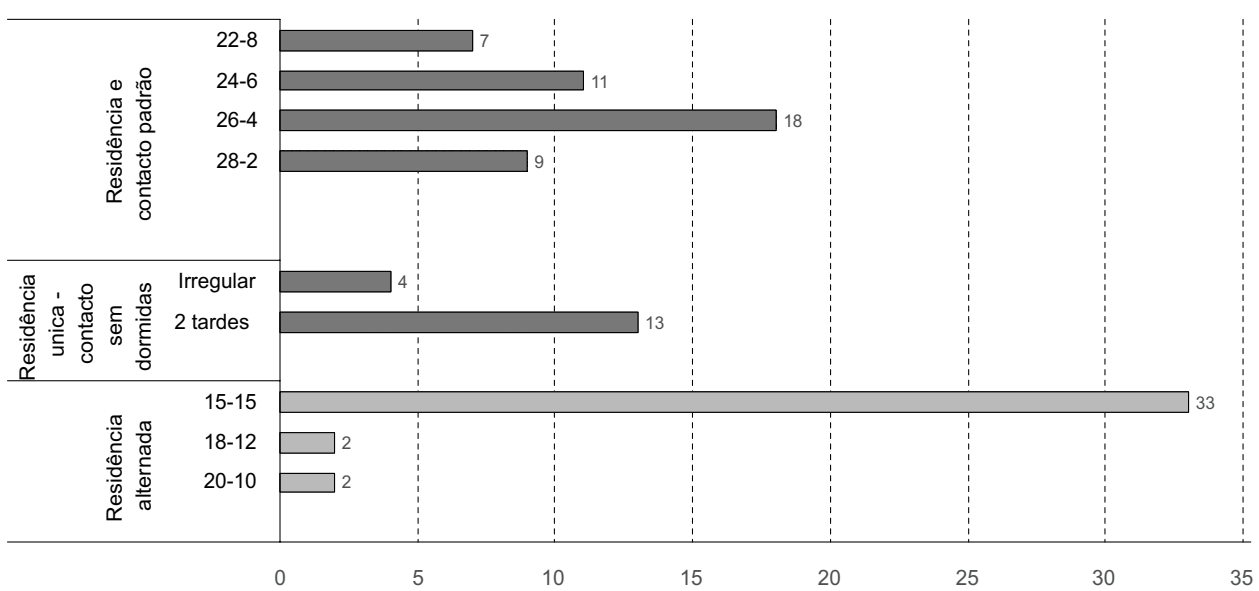

Figura 2 Modalidades de divisão das dormidas da criança na casa de cada progenitor, segundo formas de residência e de contacto $(\%)$

crianças. Revelam, ainda, como as experiências da escassez do tempo de contacto moldam a perceção que têm do seu papel parental, da sua relação com as crianças ausentes, da cooperação parental e do quadro legal. Vejamos exemplos transversais às várias modalidades de contacto padrão:

É muito difícil para mim não poder estar mais tempo com a minha filha. O tempo de partilha é muito curto e cria distâncias entre pai e filha. A resistência e oposição da mãe não permitem mudar esta situação. [Pai, ensino superior, 26-4, idade da filha: 7-11 anos]

Passo pouquíssimo tempo com o meu filho e a relação com ele é bastante dificultada por isso e pela mãe. É bastante difícil chegar a acordo sobre a alteração desta situação. [Pai, ensino secundário, 24-6, idade do filho: 7-11 anos]

Sempre fui um pai presente e, mesmo não morando na mesma casa, não deixei um minuto de ser pai. Sempre assumi essa responsabilidade e procurei e procuro desempenhar da melhor forma esse papel. As leis existentes são desajustadas e pouco atuais, estigmatizando os homens ao criar barreiras ao pai presente. São barreiras que procuro ultrapassar. [Pai, ensino secundário, 24-6, idade da filha: até 6 anos]

Manifesta-se, nestes relatos, a construção social do contacto padrão como produtor de distância entre o pai e a suas crianças. Este emerge como experiência de privação e de conformidade, vivida por homens não residentes que desejam ser pais envolvidos. Aqui reside a rejeição dos homens da expectativa social de serem meros companheiros ocasionais de fim de semana das crianças e a sua aspiração à 
paternidade tecida por interações afetivas e educativas duradouras e continuadas. Mas, como esta requer a construção de laços e cumplicidades no dia a dia das tarefas e rotinas familiares para ser desempenhada, no contacto também reside a fragilidade da paternidade não residente, fruto da dependência da duração do tempo paterno da qualidade da relação mãe-pai e da conformidade com formas tradicionais de ser pai articuladas ao nível institucional.

Contrastando com os pais não residentes, as mães avaliam as suas experiências da residência padrão apresentando tanto aspetos positivos como negativos:

Positivo: tem mais lógica as crianças terem o espaço delas e estarem com o pai ao fim de semana. Acompanho o dia a dia das minhas filhas e a nossa relação é muito próxima. Posso ser eu a decidir praticamente tudo sem ter que pedir a opinião do pai e não tenho que conviver com ele com frequência. [Mãe, ensino superior; 28-2, idade da filha: 7-11 anos]

Positivo: este modelo salvaguarda a estabilidade da criança, evitando constantes idas e vindas da casa do pai. Negativo: grande peso e responsabilidade que recai sobre mim e menor responsabilidade (com equivalente) distância em relação ao pai. [Mãe, ensino secundário; 24-6, idade da filha: 7-11 anos]

Positivo: a partilha de afetos e emoções que existe entre nós as três. Negativo: sentir a sobrecarga da responsabilidade de, sozinha, trabalhar e ser mãe e pai para amar, brincar e educar. É extenuante. O pai não conhece, não percebe nem entende as necessidades e vontades das filhas. Não as contraria, dá-lhes tudo o que querem. [Mãe, ensino superior; 26-4, idade da filha: até 6 anos]

Nos discursos das mães é notória a defesa da residência padrão enquanto garantia "natural" da "estabilidade da criança", que se contrapõe à residência alternada. Esta defesa revela a substituição da defesa da residência materna alicerçada em crenças maternalistas explícitas, pela que esgrime o argumento da imutabilidade do espaço físico onde se desenrola a vida da criança, à partida proporcionado pela mãe. A residência padrão emerge também como o palco de gratificações afetivas e identitárias, decorrentes quer da constância dos laços maternos criados nas crianças pelos cuidados e acompanhamento diários, quer de ganhos de autonomia pessoal e de poder parental face ao pai, quer, ainda, da validação social da maior credibilidade das aptidões parentais das mães. Assim, não é de estranhar que nos elementos negativos apontados conste a relação entre a sobrecarga parental materna e a incompetência paterna, pois é esta última que justifica o maior peso de tarefas e responsabilidades parentais colocado em cima dos ombros das mães, incluindo as dificuldades sentidas na articulação maternidade/trabalho.

São poucas as mães que têm outro ponto de vista sobre tal sobrecarga, registando-se aquele que a encara como consequência da desresponsabilização e distanciamento do pai da criança inerente ao regime standard. Também são poucas as que deixam a criança estar o tempo que quer com o pai, beneficiando assim da partilha parental, mesmo que as dormidas reduzidas se mantenham. 
A residência única com contacto é uma variante do regime standard, tendo sido a partir desta que se desenvolveu a residência e o contacto padrão (Smyth, 2004). Retrata as situações em que a criança não pernoita na casa do pai durante o período letivo, as quais, neste estudo, englobam o contacto quinzenal nas tardes de sábado e o contacto irregular e muito espaçado (figura 2). Em $80 \%$ dos casos a criança não passa férias com o pai $(\mathrm{p}<0,001)$. Configura, assim, a estrutura de alocação de tempo parental que mais limita o contacto da criança com o progenitor não residente.

Na descrição e avaliação que as mães fazem do primeiro, destacam-se os benefícios afetivos, identitários e de autonomia parental da mãe, resultantes da secundarização da figura paterna:

Positivo é ter sempre a guarda dele. É mais importante para o bem-estar do meu filho estar com a mãe do que estar com o pai. Negativo é a falta de responsabilidade do pai na educação e alimentação do filho. [Mãe, ensino superior, duas tardes, idade do filho: até 6 anos]

Até perfazer 6 anos a minha filha só está com o pai durante as tardes de sábado porque não deve ser separada da mãe durante mais tempo, principalmente durante a noite. Positivo: passo muito tempo com a minha filha, temos por isso uma grande cumplicidade. É fácil manter e gerir uma rotina. Não sofro a distância dela uma vez que à noite está em casa. Negativo: tenho pouco tempo para mim mesma. [Mãe, ensino superior, duas tardes, idade da filha: até 6 anos]

A partir destes excertos, percebe-se que o impedimento das dormidas da criança na casa do pai, quando não serve a proteção da criança prevista na lei, reflete o uso do género para defender a primazia materna e a incompetência paterna na relação com a criança, ou mesmo para consagrar a maternidade como "talento de género", ou seja, crenças maternalistas sobre a parentalidade (Cowdery e Knudson-Martin, 2005).

O contacto irregular tende mais a ser um desfecho do contacto padrão. É associado, pelas mães, a três tipos de trajetória de afastamento do pai: desinteresse; emigração; e mudança de residência para um local distante. O desinteresse pela criança tem sido atribuído aos obstáculos relacionais e identitários colocados a mães e a pais não residentes pelo contacto padrão (Arendell, 1995; Kruk, 2015). Já a emigração e a mudança de residência, tendem a refletir o impacto do desemprego e da recomposição familiar do pai na paternidade não residente. Nestas situações, o contacto com a criança ocorria apenas nas férias laborais do pai.

\section{$O$ regime de residência alternada}

A residência alternada classifica a residência da criança com os dois progenitores, englobando as situações em que filhos e filhas dormem $33 \%$ a $50 \%$ das noites, de um mês letivo, na casa de um dos progenitores. Neste regime, $83 \%$ das crianças tendem a partilhar férias de verão com os dois progenitores $(p<0,001)$. 
Abrange modalidades variadas de divisão do tempo de residência e de organização da rotação da criança entre a casa da mãe e a casa do pai. A figura 2 mostra que a modalidade em que o número de dormidas na casa de cada progenitor é igual, a modalidade 15-15, é a mais representada nesta amostra. Mas revelaram-se outras em que este é desigual: as modalidades 20-10 e 18-12. Nestes casos, a criança dorme menos vezes na casa do pai, mas o contrário também pode acontecer, como mostra um estudo anterior (Marinho, 2011).

A divisão 15-15 engloba as seguintes formas de organização da rotação da criança: quinzenal; semanal; semanas repartidas; e diária com fins de semana alternados. Alguns progenitores optam pela rotação entre casas e outros fazem-na através da escola, o que pode suceder por questões práticas ou para evitar encontros entre mãe e pai (Marinho, 2011).

A quinzenal é a modalidade em que há um período mais longo de afastamento de um dos progenitores, ainda que tenda a ser atenuado por uma dormida a meio da segunda semana na casa do progenitor ausente. A rotação tende a ocorrer à sexta-feira, eleita porque torna mais fácil a adaptação da criança à transição de uma casa para a outra. Na semanal, a mudança de casa tende a ocorrer à sexta-feira, pelo mesmo motivo, ou às segundas-feiras. Às vezes, inclui também uma dormida na casa do progenitor ausente a meio da semana. Nas semanas repartidas, a criança dorme segundas e terças-feiras na casa de um progenitor e quartas e quintas na casa do outro, os fins de semana (de sexta a domingo) são alternados. Por último, a rotação diária combinada com fins de semana alternados tende a ser aplicada às crianças mais pequenas (até 6 anos), sendo vista como a forma de evitar separações prolongadas da mãe ou do pai.

Quando fazem um balanço das suas experiências, a maior parte das mães e dos pais com residências alternadas simétricas ${ }^{2}$ destaca, como principais aspetos positivos, o relacionamento próximo da criança com os dois progenitores e a partilha efetiva de tempo, responsabilidades e tarefas parentais entre mãe e pai. Mas são igualmente mencionados aspetos negativos, reveladores de desafios e dificuldades vividas:

Positivo: é a única forma de crescer com os dois progenitores, sem que nenhum dos dois seja visto como uma visita. Negativo: claro que pode ser difícil, pelas diferenças e desentendimentos que possam existir entre os pais em relação a opções de educação. Não são exclusivas aos casais separados. Aprende-se a ultrapassar, com maturidade e com as estratégias certas. [Pai, ensino superior, idade do filho: 7-11 anos]

Positivo: as minhas filhas têm relações fortes comigo e com o pai e não têm apenas um pai de fim de semana. Mantêm relações frequentes com muitos familiares dos dois lados. Negativo: as saudades são difíceis, bem como a gestão do estilo de educação do pai, muito rígido do meu ponto de vista. [Mãe, ensino superior, idade da filha: 7-11 anos]

2 Os quatro progenitores com tempos desiguais de residência alternada não responderam à pergunta de balanço. 
Positivo: permite dedicar o tempo sem filha ao trabalho (no meu caso nem sempre tenho horários compatíveis com a maternidade), aos respetivos namorados e a outras atividades. É mais equilibrado em termos de esforço e mais justo para os filhos. Negativo é ter saudades da filha e nem sempre concordar com as regras da casa do pai. [Mãe, ensino superior, idade da filha: até 6 anos]

A prática da alternância de residência afasta a criança da distinção entre mãe e pai baseada na alocação do tempo parental que separa a semana do fim de semana, mesmo quando o tempo de residência é assimétrico. Deste modo, insere-a em quadros de referência de igualdade afetiva e relacional, sustentados na partilha do quotidiano com os dois progenitores. Os discursos evidenciam que esta prática assenta na recusa do regime standard, orientada pela adesão a valores de equidade e justiça, considerados essenciais quer para o bem-estar de filhos e filhas na relação destes com cada progenitor, quer para o bem-estar dos adultos no exercício da parentalidade e na conciliação família/trabalho. É notória a ausência de experiências em que o género é usado para validar papéis e identidades, ou a credibilidade de competências de um progenitor em detrimento das do outro. Mas também a de experiências de sobrecarga parental nos relatos das mães que, ao invés das mães com residência padrão, falam de equilíbrio: emocional; na partilha parental; e na conciliação entre a maternidade, a vida pessoal e o trabalho. Também os homens falam de experiências de equilíbrio emocional e parental, embora estas se coloquem mais por comparação com as experiências de privação, suas e das suas crianças, que o contacto padrão poderia acarretar. Nos aspetos negativos apresentados, predominam quer as saudades provocadas pela ausência da criança, só referidas pelas mães, quer os desafios e as dificuldades relacionais colocados por estilos parentais diferentes. Embora possa articular críticas mútuas de opções e desempenhos educativos, a referência à discordância com o estilo parental do outro surge associada à ideia de que é um desafio inerente à própria coparentalidade, ou seja, de que esta tem de ser aceite e, se possível, negociada entre mãe e pai, seja em casal, seja após divórcio.

\section{Escolaridade, residência e não residência}

Importa ainda olhar para a inserção dos regimes de divisão do tempo parental na estrutura de recursos sociais, o que farei observando como estes se relacionam com o nível de escolaridade de mães e de pais.

A figura 3 retrata, sobretudo, a transversalidade social do divórcio/separação e do quadro de valores e normas que sustenta o regime standard. Deste modo, esta reflete as diferenças nos níveis de educação de mulheres e de homens na sociedade portuguesa (ver Rodrigues, Cunha e Wall, 2015). Talvez por isso, não se revelaram associações significativas entre níveis de escolaridade e a residência padrão e única das mulheres com as crianças, e os estudos superiores têm um maior peso junto das mulheres residentes. Ao invés, no grupo de pais não residentes os níveis de escolaridade até ao 12. ${ }^{\circ}$ ano estão sobrerrepresentados (r.p. 3,0; p<0,01). 


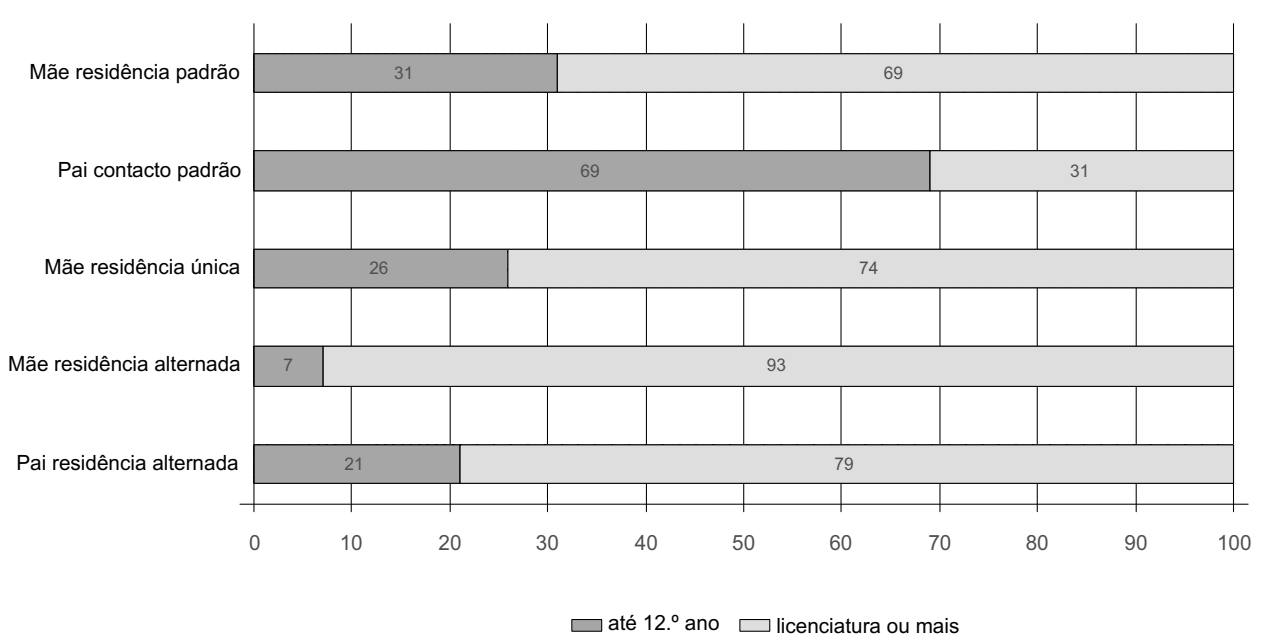

Figura 3 Escolaridade das mães e dos pais inquiridos, segundo formas de residência e de contacto (\%)

Em contrapartida, na residência alternada os níveis de escolaridade até ao 12.. ano tendem a estar sub-representados (r.p. $-2,0 ; p<0,05$ ), observando-se que os estudos superiores registam um maior peso relativo. Assim, a alternância de residência poderá estar a disseminar-se de forma mais expressiva nos grupos sociais mais escolarizados, revelando que a participação na transformação dos modelos tradicionais de maternidade e de paternidade (Marinho, 2011, 2017; Neyrand, 2009) é facilitada pela posse de recursos e competências sociais associados à escolaridade. A identificação com novos modelos culturais de paternidade (Marinho, 2011, 2017) também é vivida pelos pais não residentes, traduzindo-se nas experiências de privação e de conformidade, que tendem a estar associadas a posições sociais mais desprovidas de recursos escolares

\section{Residência, contacto e responsabilidades parentais}

Ao ser associado ao regime-regra das responsabilidades parentais partilhadas, o regime de residência e não residência com contacto foi confrontado com dois corolários do princípio das responsabilidades parentais partilhadas, presentes na Lei N. 61/2008: "manter uma relação de grande proximidade com os dois progenitores"; e favorecer "amplas oportunidades de contacto com ambos". ${ }^{3}$ Porém, a solução privilegiada para os concretizar manteve-se dentro das fronteiras estipuladas pela ordem tradicional deste regime. Ainda assim, as modalidades de residência e de contacto que este encerra tendem a variar em função da atribuição de responsabilidades parentais 


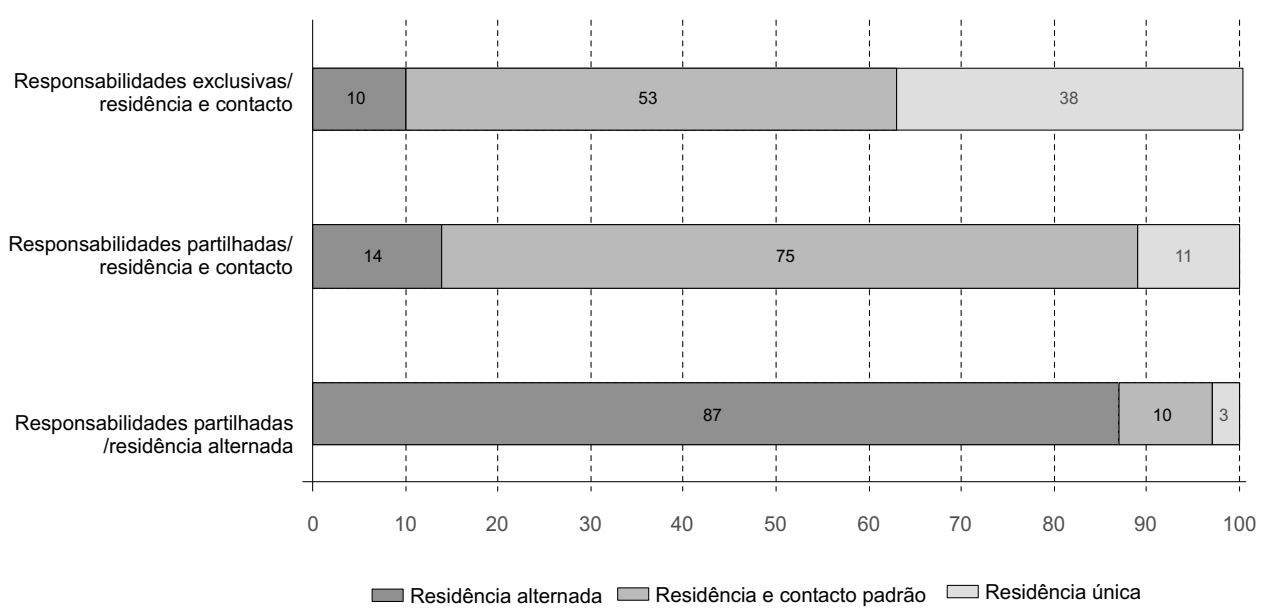

Figura 4 Responsabilidades parentais legais, segundo modalidades de residência e de contacto (\%)

partilhadas ou exclusivas, que coexistem na aplicação da lei, como se mostra na figura 4.

Com efeito, as responsabilidades parentais partilhadas tendem mais a associar-se às modalidades de contacto 24-6 e 22-8 $(\mathrm{p}<0,001)$ do que às demais, sugerindo que a partilha legal de responsabilidades parentais pode estar a conduzir ao aumento do tempo de contacto. Este resultado é consistente com o estudo de Smyth (2004), que o associa à valorização social do envolvimento do pai. Porém, dado que a partilha de responsabilidades abriga igualmente tipos de contacto mais restritivos, os dados sugerem que este aumento tende a estar refém dos quadros de referência simbólica e prática de quem aplica a lei, visivelmente díspares quanto ao papel do pai e às necessidades da criança.

$\mathrm{Na}$ atribuição de responsabilidades parentais exclusivas, ainda com peso significativo na regulação de acordos parentais (Pedroso, Casaleiro e Branco, 2014), prevalecem as modalidades de contacto 28-2 e 26-4. Mas também o convívio quinzenal da criança com o pai nas tardes de sábado, elemento fulcral para a formação da residência única, como referido. Este foi configurado judicialmente em $70 \%$ dos acordos parentais, dos quais $45 \%$ foram regulados no âmbito da nova lei. Tanto quanto nos é dado a conhecer pelas mães, o que estava em causa na negociação do acordo de divisão do tempo parental era a maior necessidade da mãe do que do pai por parte de crianças "até 6 anos", tal como demonstrado na secção anterior. Tudo indica então que algumas decisões judiciais estão, por um lado, a dar abrigo a crenças maternalistas tradicionais reconfiguradas, nas quais as dormidas na casa do pai das crianças mais pequenas deixam de ser consideradas desnecessárias como outrora, para passarem a ser vistas como prejudiciais para o bem-estar destas e, por outro lado, a resistir à aplicação do regime-regra de responsabilidades partilhadas. 
Apesar de a residência alternada não estar explicitamente contemplada na lei, mostra a figura 4 que mães e pais têm conseguido a homologação de acordos de responsabilidades parentais partilhadas em que a residência é alternada. Neste estudo, $64 \%$ destes acordos foram regulados judicialmente no quadro da nova lei e $5 \%$ no quadro da lei anterior. Os restantes não passaram pelo crivo judicial, pois resultam de acordos privados entre casais coabitantes ou da negociação entre progenitores da transformação de residências padrão e únicas em residências alternadas. Alguns dos acordos de residência alternada também se transformaram em residências padrão ou únicas. Porém, pelo menos nesta amostra, estas trajetórias de um regime de residência para outro estão estatisticamente sub-representadas $(\mathrm{p}<0,001)$, sugerindo, assim, que a maioria das parcerias parentais tende a manter-se fiel às regras estipuladas pelos acordos parentais negociados aquando da separação.

\section{Conclusões}

Ao averiguar as dimensões sociais da alocação do tempo parental após divórcio/separação, este artigo identificou práticas de divisão do tempo das crianças com cada progenitor e significados atribuídos aos papéis parentais e à relação com as crianças, nas experiências da residência e do contacto de mães e de pais e na aplicação da lei em Portugal. Tendo em conta os objetivos e questões de pesquisa que orientaram o estudo, neste ponto conclusivo assinalam-se os seus principais traços.

A diversidade encontrada nas práticas, nos significados e nas experiências de divisão do tempo parental e a evidência de que esta se pronuncia, sobretudo, dentro das fronteiras delimitadas por cada um dos regimes de residência identificados, criando a sua coexistência relações sociais paradoxais inerentes a processos de mudança cultural em curso, revelam uma realidade pouco conhecida em Portugal. Com efeito, os resultados indicam que tanto o regime standard como o de residência alternada estão vinculados a fundamentos normativos e valorativos de proteção dos laços da criança com os dois progenitores, porém, cada regime representa um universo simbólico e prático particular, pois orienta de forma distinta as relações sociais entre o tempo parental, a maternidade, a paternidade e o bem-estar da criança após divórcio/separação.

No regime de residência e contacto, a alocação de tempo parental permanece genderizada como outrora, pois diferencia os papéis parentais de mulheres e de homens e a relação destes com a criança, distinguindo o tempo do cuidar materno continuado, no dia a dia da semana e do fim de semana, do tempo do companheirismo paterno (Singly, 2000), curto e concentrado no fim de semana do contacto quinzenal. No regime de residência alternada, a alocação de tempo parental afasta-se de tal distinção, ao unir o tempo semanal e de fim de semana em períodos suficientemente longos para inserir a criança em quadros de igualdade afetiva e relacional, sustentados na partilha do quotidiano com os dois progenitores.

Tornou-se visível que, tal como avançou Smyth (2004), a atribuição de responsabilidades parentais partilhadas fomentou pequenos aumentos no tempo de 
contacto alocado à paternidade não residente, tendencialmente regulada por duas a quatro dormidas mensais (28-2 e 26-4): de uma dormida, na semana de afastamento (24-6) e, nalguns casos emergentes, também ao fim de semana (22-8). Contudo, indo ao encontro do estudo de Pedroso, Casaleiro e Branco (2014), os resultados mostram igualmente que tal aumento é preterido, em alguns tribunais, em favor do contacto mais restritivo, revelando visões díspares da importância do envolvimento paterno na aplicação da lei. Logo, na alocação e calendarização do contacto continua-se a restringir a variedade de contextos e a continuidade das interações da criança com o progenitor não residente, propiciando, como evidenciado igualmente na literatura, relações com a criança enfraquecidas e dificuldades no exercício de responsabilidades parentais (Arendell, 1995; Hallman, Dienhart e Beaton, 2007; Kruk, 2010, 2015).

Por isso, os homens não residentes mostraram que o tempo de contacto pode ser vivido como privação parental e identitária, sua e das crianças - tal como demonstrado por Hallman, Dienhart e Beaton (2007). Mas também como experiência de conformidade com formas tradicionais de ser pai, articuladas pela lei e pela dependência do tempo paterno da qualidade da relação mãe-pai. Desta forma, este estudo identifica obstáculos institucionais colocados às paternidades tecidas por interações com a criança mais duradouras e constantes, sendo estes mais prementes perante posicionamentos sociais de baixos recursos.

Verificou-se que as mulheres vivem experiências afetivas e identitárias gratificantes no tempo de residência, tecidas pela constância dos cuidados e laços maternos, pelos ganhos de autonomia e poder parental face ao pai e pela validação social das suas aptidões parentais. Vivem também a sobrecarga parental, como mostrado por Cardoso (2014). O que é pouco conhecido é esta ser sustentada na crença de que é justificada, face a entendimentos da incompetência paterna e da "instabilidade" criada na criança pela alternância de residência. Cabe, então, perguntar se o suporte de tal crença não será a disputa pela credibilidade social de papéis, identidades e aptidões parentais assentes no género, promovida pelos obstáculos institucionais colocados às mudanças na paternidade não residente e na maternidade residente. $\mathrm{O}$ mesmo se coloca face à residência única formada pelo impedimento das dormidas da criança na casa do pai, prática que se mostrou estar ancorada na fundamentação da atribuição de responsabilidades exclusivas em crenças maternalistas, ao invés da atribuição de responsabilidades parentais partilhadas como previsto na lei.

Com diferentes calendários de rotação da criança e alocações de tempo parental, simétrico ou não, as práticas de alternância de residência inserem sempre a relação com a criança nos contextos temporais das interações do quotidiano, como assinalado por Smyth (2004). Percebeu-se que têm encontrado algum abrigo na aplicação da lei, mas este não é certo nem é para todos, dado ser uma prática que estabelece fissuras na ordem de género tradicional que sustenta o regime standard, requerendo, por isso, recursos e competências sociais para ser validada. Com efeito, esta trata de recusar tal regime, incorporando na alocação de tempo parental a equidade e a justiça na divisão de cuidados e de responsabilidades. Mulheres e homens vivem, deste modo, experiências de equilíbrio emocional e parental, na 
relação das crianças com cada progenitor e com a família alargada de cada um, bem como na articulação família/trabalho e vida pessoal, aliás já demonstradas noutros estudos (Neyrand, 2009; Nielsen 2011). Mas também vivem dificuldades na articulação de estilos parentais, ou na aceitação de um estilo diferente do seu, desafios que podem envolver divergências e críticas mútuas de desempenhos e escolhas educativas. Porém, estas acabam por ser colocadas no seio das vivências negociais inerentes à parentalidade, em vez de no plano das disputas de papéis e identidades assentes no género que habitam o regime standard.

Por fim, importa assinalar que o desequilíbrio entre o número de mães e de pais e na composição social da amostra, assim como o tamanho desta, excluíram da análise parte do leque de experiências e de práticas. As experiências do tempo parental de pais não residentes que aceitam a estrutura de contacto e daqueles que vivem a residência padrão e única, bem como as experiências de mães não residentes com contacto com as crianças permaneceram na sombra.

\section{Referências bibliográficas}

Arendell, Terry (1995), Fathers \& Divorce, Thousand Oaks, CA, Sage Publications.

Atalaia, Susana (2014), "As famílias recompostas em Portugal: dez anos de evolução (2001-2011)", em Ana Delgado e Karin Wall (orgs.), Famílias nos Censos 2011. Diversidade e Mudança, Lisboa, INE e ICS-UL, pp. 225-239.

Bastaits, Kim, Koen Ponnet, e Dimitri Mortelmans (2012), "Parenting of divorced fathers and the association with children's self-steem", Journal Youth and Adolescence, 41 (12), pp. 1643-1656.

Cardoso, Sónia (2014), Conciliação Famíia-Trabalho em Famílias Monoparentais. Uma Abordagem Comparativa de Género, Lisboa, Universidade de Lisboa, tese de doutoramento, disponível em: http://repositorio.ul.pt/handle/10451/10800 (última consulta em novembro de 2016).

Cowdery, Randi, e Carmen Knudson-Martin (2005), “The construction of motherhood: tasks, relational connection, and gender equality", Family Relations, 54 (3), pp. 335-345.

Daly, Kerry (1996), Families \& Time. Keeping Pace in a Hurried Culture, Thousand Oaks, CA, Sage Publications.

Deutsch, Francine (2007), “Undoing gender”, Gender \& Society, 21 (1), pp. 106-127.

Escobedo, Anna, Lluís Flaquer, e Lara Navarro-Varas (2012), “The social politics of fatherhood in Spain and France: a comparative analysis of parental leave and shared residence", Ethnologie Française, 42 (1), pp. 117-126.

Hallman, Mara, Anna Dienhart, e John Beaton (2007), "A qualitative analysis of fathers' experiences of parental time after separation and divorce", Fathering, 5 (1), pp. 4-24.

Hodgson, Judaline, Anna, Dienhart, e Kerry Daly (2001), "Time juggling", Journal of Divorce and Remarriage, 35 (1-2), pp. 1-28.

Kaufmann, Jean-Claude (1994), "Rôles et identité: l'exemple de l'entrée en couple", Cahiers Internationaux de Sociologie, XCVIII, pp. 301-328. 
Kruk, Edward (1991), “Discontinuity between pre- and post-divorce father-child relationships: new evidence regarding paternal disengagment", em Everett Craig (org.), The Consequences of Divorce, Bridgehampton, NY, The Haworth Press, pp. 195-228.

Kruk, Edward (2010), "Parental and social institutional responsibilities to children's needs in the divorce transition: fathers' perspectives", The Journal of Men's Studies, 18 (2), pp. 159-178.

Kruk, Edward (2015), “The lived experiences of non-custodial parents in Canada: a comparison of mothers and fathers", International Journal for Family Research and Policy, 1 (1), pp. 80-95.

Lamb, Michael (2010), “How do fathers affect children's development? Let me count the ways", em Michael Lamb (org.), The Role of the Father in Child Development, Hoboken, NJ, John Wiley \& Sons, pp. 1-26.

Marinho, Sofia (2011), Paternidades de Hoje. Significados, Práticas e Negociações da Parentalidade na Conjugalidade e na Residência Alternada, Lisboa, Universidade de Lisboa, tese de doutoramento em Ciências Sociais, especialidade de Sociologia Geral, disponível em: http://repositorio.ul.pt/handle/10451/4940 (última consulta em novembro de 2016).

Marinho, Sofia (2014), "Famílias monoparentais: linhas de continuidade e de mudança", em A. Delgado e K. Wall (orgs.), Famílias nos Censos 2011. Diversidade e Mudança, Lisboa, INE e ICS-UL, pp. 177-195.

Marinho, Sofia (2017), "Separate mothering and fathering: the plurality of parenting within the framework of post-divorce shared parenting norms", Journal of Divorce $\mathcal{E}$ Remarriage, 58 (4), pp. 288-309.

Morgan, David (2011), Rethinking Family Practices, Nova Iorque, Palgrave Macmillan. Neyrand, Gérard (2009), Le Dialogue Familial, Un Idéal Précaire, Toulouse, Erès.

Nielsen, Linda (2011), "Shared parenting after divorce: a review of shared residential parenting research", Journal of Divorce E Remarriage, 52 (8), pp. 586-609.

Nielsen, Linda (2014), "Shared physical custody: summary of 40 studies on outcomes for children", Journal of Divorce \& Remarriage, 55, pp. 614-636.

O'Brien, Margaret (2004), "Shared caring: bringing fathers into the frame", EOC Working Papers N.o 18, Manchester, Equal Opportunities Commission.

Oliveira, Guilherme (2017), “A "residência alternada" em Portugal, segundo a lei n. 61/2008", em Sofia Marinho e Sónia V. Correia (org.), Uma Família Parental, Duas Casas. Residência Alternada - Dinâmicas e Práticas Sociais, Lisboa, Edições Sílabo, pp. 149-162.

Pedroso, João, Paula Casaleiro, e Patrícia Branco (2014), “A (des)igualdade de género nos Tribunais de Família e Menores: um estudo de sentenças de regulação das responsabilidades parentais em Portugal", Estudos de Sociologia, 19 (36), pp. 81-100.

Rodrigues, Leonor, Vanessa Cunha, e Karin Wall (2015), Homens, Papéis Masculinos e Igualdade de Género, Lisboa, CITE.

Singly, François (2000), O Eu, o Casal e a Família, Lisboa, Publicações Dom Quixote.

Smyth, Bruce (2004), "Parent-child contact schedules after divorce", Family Matters, 69, pp. 32-42. 
Sofia Marinho. Socióloga, investigadora doutorada no Instituto de Ciências Sociais da Universidade de Lisboa, Lisboa, Portugal. E-mail: scmarinho@ics.ul.pt

Receção: 24 de novembro de 2016 Aprovação: 15 de julho de 2017 
